\title{
Survival rates of hirundines in relation to British and African rainfall
}

\author{
ROBERT A. ROBINSON*, DAWN E. BALMER and JOHN H. MARCHANT \\ British Trust for Ornithology, The Nunnery, Thetford, Norfolk IP24 2PU, UK
}

The BTO's Retrapping Adults for Survival scheme is designed to monitor survival rates of species of conservation concern that are monitored relatively poorly by other forms of ringing. Here we present temporal trends in survival rates for three hirundine species, Barn Swallow Hirundo rustica, House Martin Delichon urbicum and Sand Martin Riparia riparia. Estimates of apparent survival rate were similar to those found in previous studies and were correlated with rainfall on the African wintering grounds, but not with rainfall in Britain, suggesting that overwinter food resources may be more limiting.

There is currently concern over the population status of Palaearctic-African migrants in Europe, as most of these species have shown consistent population declines over the last 30 years; particularly amongst species inhabiting open, dry habitats in Africa (Sanderson et al 2006). At a European scale both Sand Martin Riparia riparia and Barn Swallow Hirundo rustica declined in numbers between 1970 and 1990 but not subsequently, whereas House Martin Delichon urbicum numbers showed no change between 1970 and 1990, but have since shown a significant decline (Sanderson et al 2006). In England, Swallow numbers have fluctuated markedly over the last 30 years (Robinson et al. 2003), while declines have been observed recently in numbers of Sand Martin (1997-2004) and House Martin (1984-94) (Baillie et al 2007).

All three species are widely distributed in Britain but they winter in different parts of Africa (Cramp 1988). They all share a broadly similar ecology; in particular they feed on aerial invertebrates on both the breeding and nonbreeding grounds. The abundance of these is well known to be positively related to rainfall (eg Wolda 1978, Frampton et al 2000). This relationship is likely to be strong in arid areas, such as the Sahel, where many British migrants pass through on migration or spend the winter (Wernham et al 2002). Consequently, one might expect rainfall to have a significant effect on annual survival rates, as has already been demonstrated for Sand Martin (eg Cowley $\&$ Siriwardena 2005) and for a number of other migrant species, such as warblers (eg Peach et al 1991, Szép 1995, Sherry \& Holmes 1996).

The British Trust for Ornithology's (BTO) Retrapping Adults for Survival (RAS) scheme was started in 1998 to monitor the survival rates of species of conservation concern that are not well monitored by other forms of ringing. For most small-bodied long-distance migrants, the recovery rates from general ringing are too low to provide

* Correspondence author

Email rob.robinson@bto.org precise estimates of survival rates, and many species do not occur in the habitats covered by the Constant Effort Sites ringing programme (CES, Peach et al 1996), where retrapping of live birds increases the precision of the survival estimates considerably. A number of species monitored by RAS are migrants: in particular, RAS projects are operated for all three common hirundine species in Britain. Although large numbers of hirundines are ringed each year in Britain, most of these are caught at autumn migration roosts, which may comprise birds originating over a wide area, including continental Europe (eg Crick et al 1977). RAS aims to focus efforts on ringing species at breeding colonies, thus providing information on adult birds of known origin from which to estimate survival rates. Here we present initial results from the RAS scheme describing adult survival rates in the three hirundine species, and explore the influence of rainfall on the breeding or wintering grounds in determining patterns of annual adult survival.

\section{METHODS}

The BTO's Retrapping Adults for Survival scheme began formally in 1998, but many ringers had essentially been following RAS methodology for some years previously, and we include these data where possible (for Sand Martin enough sites had data back to 1990, for House Martin back to 1994). RAS ringers operate within a defined study area, usually a continuous area of suitable breeding habitat often set within a wider matrix of less suitable or unsuitable habitat. The aim each breeding season is to ring, retrap or resight each adult breeding bird (ie all breeding pairs) on the site. RAS ringers are actively encouraged to operate their project annually for a minimum of five years, preferably longer. Sites may appear and disappear from the time series, although missing years within a time series are unusual. 
For these analyses we considered projects with five or more years of data, of which there were 11: four sites each for Sand Martin and Swallow and three sites for House Martin (Fig 1). A number of additional projects contribute data to the RAS scheme for these species, but had not at the time of these analyses completed five years' operation; in the future these sites will contribute, and strengthen the scope of monitoring.

\section{Survival rate estimation}

Apparent adult survival rates were estimated using the program MARK 4.3, based on the standard CormackJolly-Seber (CJS) model (Lebreton et al 1992, White \& Burnham 1999). Because each study is restricted to a relatively limited area (though this often encompasses the majority of the suitable breeding habitat in the area), true survival rates cannot be estimated, as any permanent emigration from the breeding area will be confounded with mortality. However, for most short-lived passerines at least, fidelity to a breeding site is high, with relatively limited movement between seasons (Paradis et al 1996).

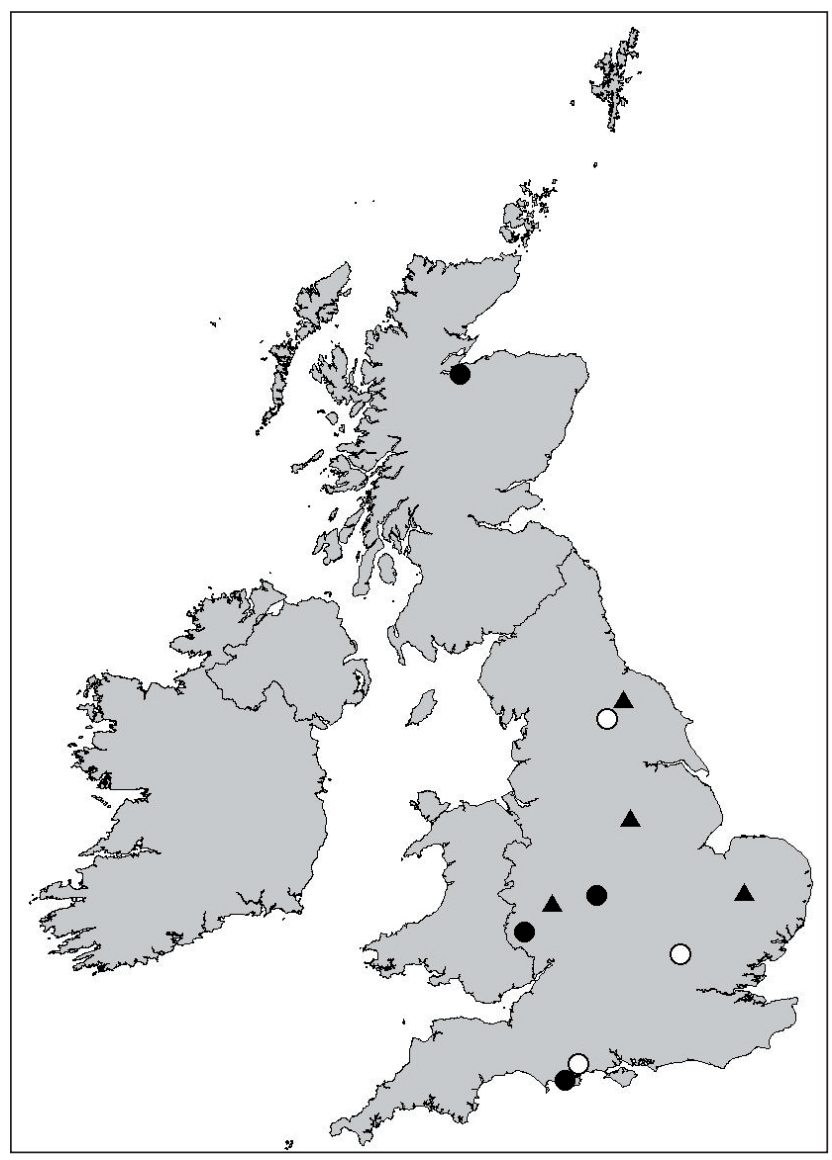

Figure 1. Location of RAS projects contributing to the analyses. Open circles are House Martin sites, closed circles Sand Martin sites and triangles Swallow sites.
Before formal modelling, we tested the goodness-of-fit of the CJS model to the recapture histories from each site using the 'Release' tests provided in MARK (Burnham et al 1987). This showed that the basic CJS model provided an acceptable fit for each species, with the overdispersion parameter ( $(\hat{)})$ less than 1.2 in each case. In particular, there were few problems of transience, where birds are caught fewer times than expected, because RAS ringers focus on particular breeding populations.

In referring to the models fitted, we follow a similar notation to that used by Lebreton et al (1992). In particular, we fitted models (separately for each species) where survival $(\phi)$ and recapture $(p)$ probabilities vary between sites (denoted s) and year ( $\mathrm{t}$ ). Variation between years, in either survival or recapture, may occur independently between sites $\left(s^{*} \mathrm{t}\right)$, or similarly (in parallel) across sites $(\mathrm{s}+\mathrm{t}$ ), in which case the annual variation is the same across sites, but the mean survival differs. If a site was not operated in a given year, the recapture probability was fixed at zero for that year (most often at the start or end of the time series for a site to match up years with the other sites).

Survival rates were modelled initially as site- and timespecific $\left(\right.$ model $\left.s^{*} t\right)$. We then constructed a model with a site-specific intercept and annual deviations from this intercept in parallel across sites (model $\mathrm{s}+\mathrm{t}$ ), to estimate the average survival rate across all sites. This model is the one of most interest, as it provides the annual pattern of variation in survival, taking into account differences in survival between sites (perhaps because of habitat quality, for instance). To test whether survival rates differed between years (individually) we compared a model with annual time variation $(\mathrm{s}+\mathrm{t}$ for Sand Martin and Swallow or $\mathrm{s}^{*} \mathrm{t}$ for House Martin, see below) with a model in which survival varied linearly with time, either in parallel or differently between sites, as appropriate.

We used Akaike's Information Criterion (AIC) to select between the different survival/recapture-rate models and likelihood ratio $\left(\chi^{2}\right)$ tests to assess the significance of differences between particular models. The AIC provides a relative measure of model fit allowing for the number of parameters used. A lower value indicates a more parsimonious model (better fit for the number of parameters used), and a difference in value of at least 2 signifies a substantially more parsimonious model.

\section{Rainfall data}

Summer rainfall data were obtained by extracting monthly totals for June, July and August from the England \& Wales precipitation index (Wigley \& Jones 1987) and calculating minimum, mean and maximum monthly rainfall for each year. For winter rainfall, we used the CRU_TS_2.1 gridded monthly rainfall data set (Mitchell \& Jones 2005) and extracted data relevant to the wintering range of each 
species (based on information in Wernham et al 2002). For Sand Martin, which winters in the western Sahel, we took an area bounded by (in the southwest) $5^{\circ} \mathrm{N} 15^{\circ} \mathrm{W}$ and (northeast) $17^{\circ} \mathrm{N} 0^{\circ} \mathrm{W}$ and for House Martin, which winters farther east, the area $5^{\circ} \mathrm{N} 0^{\circ} \mathrm{W}$ to $17^{\circ} \mathrm{N} 15^{\circ} \mathrm{E}$ was delimited. For each of these areas we extracted rainfall data for each month of the wet season (May to September) and calculated the mean, minimum and maximum monthly rainfall for each year. Because British Swallows winter in southern Africa, we also calculated mean, minimum and maximum monthly rainfall for October to December (the rainy season) for the area $35^{\circ} \mathrm{S} 15^{\circ} \mathrm{W}$ to $25^{\circ} \mathrm{S} 35^{\circ} \mathrm{W}$ (from information in Wernham et al 2002).

Unfortunately, winter rainfall figures were available only for the period 1990-2002, so we could not fit these relationships directly in MARK (using all the survival data). Instead, we simply regressed survival on rainfall; weighting each point (annual survival estimate) by the inverse of its

Table 1. Models of adult survival rates fitted for three hirundine species. Models test for differences in survival rates ( $P$, first three lines) or recapture rates $(P$, final two lines) due to variation between sites $(s)$ or year (t). Numbers are used in the text to refer to particular models; see the text for full details of each model. For each species we also indicate the total numbers of adult birds caught and years the sites were operated, in aggregate.

\begin{tabular}{|c|c|c|c|c|}
\hline & $\mathrm{n}$ & $\begin{array}{c}\text { No of } \\
\text { parameters }\end{array}$ & $\mathrm{AlC}$ & $\begin{array}{l}\text { Residual } \\
\text { deviance }\end{array}$ \\
\hline House Martin & $1,528 / 29$ & & & \\
\hline 1. $\phi_{t} p_{s}{ }^{*} t$ & & 40 & 90.6 & 201.5 \\
\hline 2. $\phi_{s+t} p_{s^{*}+}$ & & 42 & 89.9 & 196.6 \\
\hline 3. $\phi_{s * t} p_{s * t}$ & & 55 & 87.2 & 166.2 \\
\hline 4. $\phi_{s^{*}+} p_{s}$ & & 32 & 95.4 & 223.0 \\
\hline 5. $\phi_{s^{*}+} p_{s^{*}+}$ & & 55 & 87.2 & 166.2 \\
\hline Sand Martin & $12,607 / 45$ & & & \\
\hline 1. $\phi_{t} p_{s^{*} t}$ & & 58 & 301.5 & 411.8 \\
\hline 2. $\phi_{s+t} p_{s * t}$ & & 61 & 305.6 & 409.7 \\
\hline 3. $\phi_{s^{*}+} p_{s^{*}}$ & & 83 & 345.2 & 404.9 \\
\hline 4. $\phi_{s^{*}+} p_{s}$ & & 47 & 380.2 & 512.5 \\
\hline 5. $\phi_{s^{*}+} p_{s^{*} t}$ & & 83 & 345.2 & 404.9 \\
\hline Barn Swallow & 1079 / 24 & & & \\
\hline 1. $\phi_{\mathrm{t}} p_{\mathrm{s}}$ & & 11 & 7.5 & 134.5 \\
\hline 2. $\phi_{s+t} p_{s}$ & & 14 & 2.7 & 123.6 \\
\hline 3. $\phi_{s^{*}+} p_{s}$ & & 27 & 18.3 & 112.2 \\
\hline 4. $\phi_{s^{*}+} p_{s}$ & & 27 & 18.3 & 112.2 \\
\hline 5. $\phi_{s^{*}+} p_{s^{*} \dagger}$ & & 44 & 22.4 & 79.9 \\
\hline
\end{tabular}

variance to account for the fact that survival in some years was estimated more precisely than in others.

\section{RESULTS}

For Sand Martin and House Martin, AIC indicated that trapping effort varied over time on each site (comparing

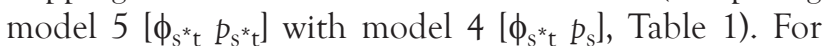
Swallow there was less evidence for differences in effort between years so we used a simpler model that assumed a constant recapture probability across years. Average apparent survival rates between years for adults of the three species were broadly similar (House Martin $\phi=0.367 \pm$ 0.053 , Sand Martin $\phi=0.303 \pm 0.014$; Barn Swallow $\phi=$ $0.404 \pm 0.028$ ), survival being averaged across time from model 2.

For Sand Martin there was no evidence of differences between sites in annual variation in survival rates (model 1 $\left[\phi_{\mathrm{t}}\right]$ had the lowest AIC), while for Swallow average survival rate varied between sites, but the pattern of variation between years was similar across sites (model $2\left[\phi_{\mathrm{s}^{+} \mathrm{t}}\right]$, Table 1). For House Martin the situation was more complex, with AIC indicating the most parsimonious model contained both site- and time-specific variation (model $3\left[\phi_{\mathrm{s}^{*} \mathrm{t}}\right]$ ). However, the actual pattern in survival rates through time at each of the sites was broadly similar (Fig 2), with differences apparent mostly between the northern and two southern sites. Indeed, a model with survival rates similar at the two northern sites (but with site-specific intercept) and different at the southern site was markedly more parsimonious $(\mathrm{AIC}=82.1)$.

For both Swallow and Sand Martin, there was significant annual variation in survival rates (Swallow: $\chi^{2}=11.0, p=$ 0.05 , Sand Martin $\left.\chi^{2}=24.6, P<0.02\right)$. However, for House

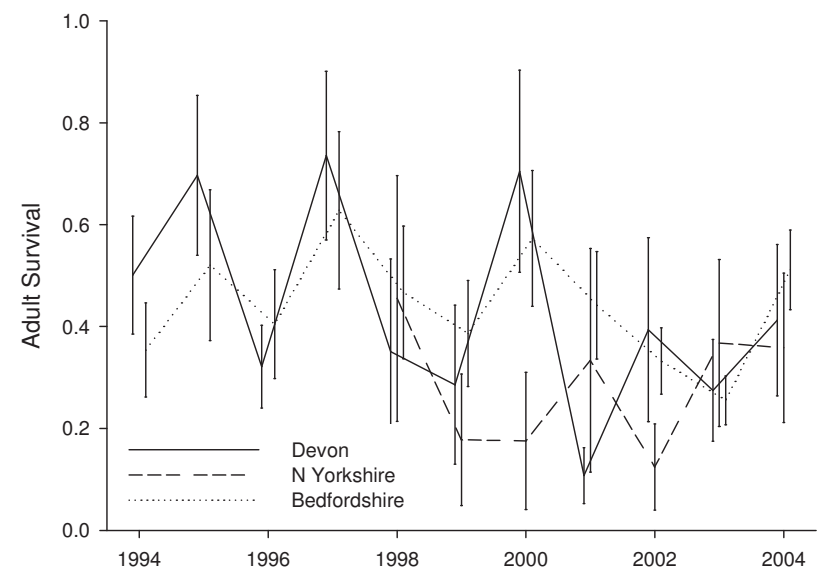

Figure 2. Adult survival at three RAS sites for House Martin from

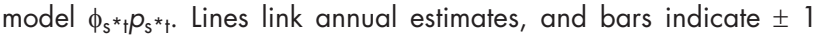
standard error. 
Martin, a simple linear trend provided a sufficient fit to the data $(\mathrm{AIC}=82.0$ ); over the period observed, survival declined significantly (slope $=-0.086 \pm 0.029, \chi^{2}=7.82, P$ $=0.02$ ). There appears to be little similarity in the annual pattern of variation in survival between the three species (Fig 3), which suggests that variables on the wintering grounds may be more important in determining annual variation in survival than those on the breeding grounds. Indeed, there was no apparent relationship with summer rainfall in Britain (monthly mean, minima or maxima) for any of the three species (all $\mathrm{R}^{2}<0.05$ ). However, for each species, rainfall in either western (House and Sand Martin) or southern (Swallow) Africa was correlated with annual variation in survival (all $R^{2} \geq 0.50$ ). For Sand Martin, minimum monthly rainfall was the best predictor, for House Martin maximum monthly rainfall, and for Swallow mean monthly rainfall, in the wintering area appropriate for each species (Fig 4).

\section{DISCUSSION}

Given their similar ecology, it is perhaps not surprising that the three species have similar overall apparent survival rates, although there seems to be little correspondence between the three species in year-to-year variation in survival. The differences in average survival rate between species may be attributable to differences in return rates between the species. Swallows are known to be highly site faithful (Turner 2006), martins perhaps less so (Cramp 1988). The estimates of survival are similar to those of previous mark-recapture studies, eg for Sand Martin $\phi_{\mathrm{ad}}$ $=0.289-0.312$ (Cowley \& Siriwardena 2005) and for Swallow $\phi_{\mathrm{ad}}=0.356-0.372$ (Møller \& Szép 2005). These estimates of return rates are surprisingly close to the

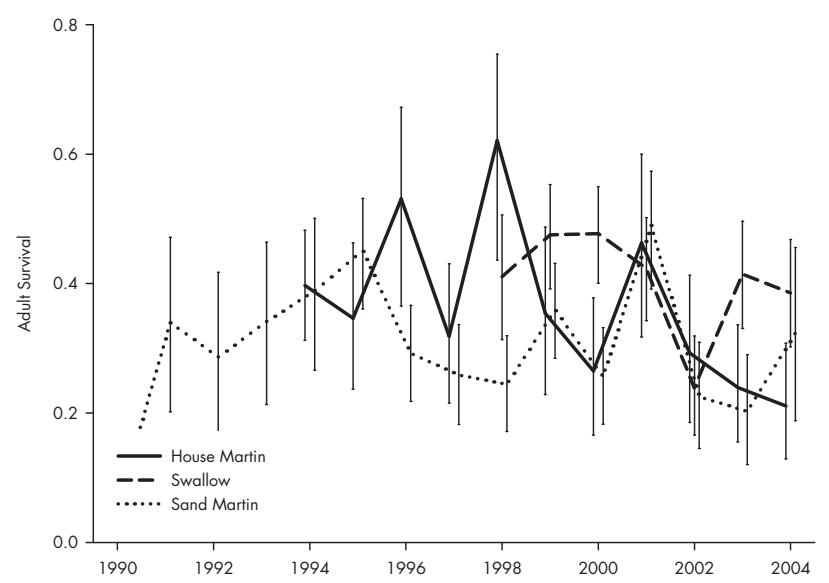

Figure 3. Adult survival at RAS sites for three species of hirundine from model $\phi_{s+t} p_{s^{*}+}$ for each species. Lines link annual estimates, and bars indicate \pm 1 standard error.
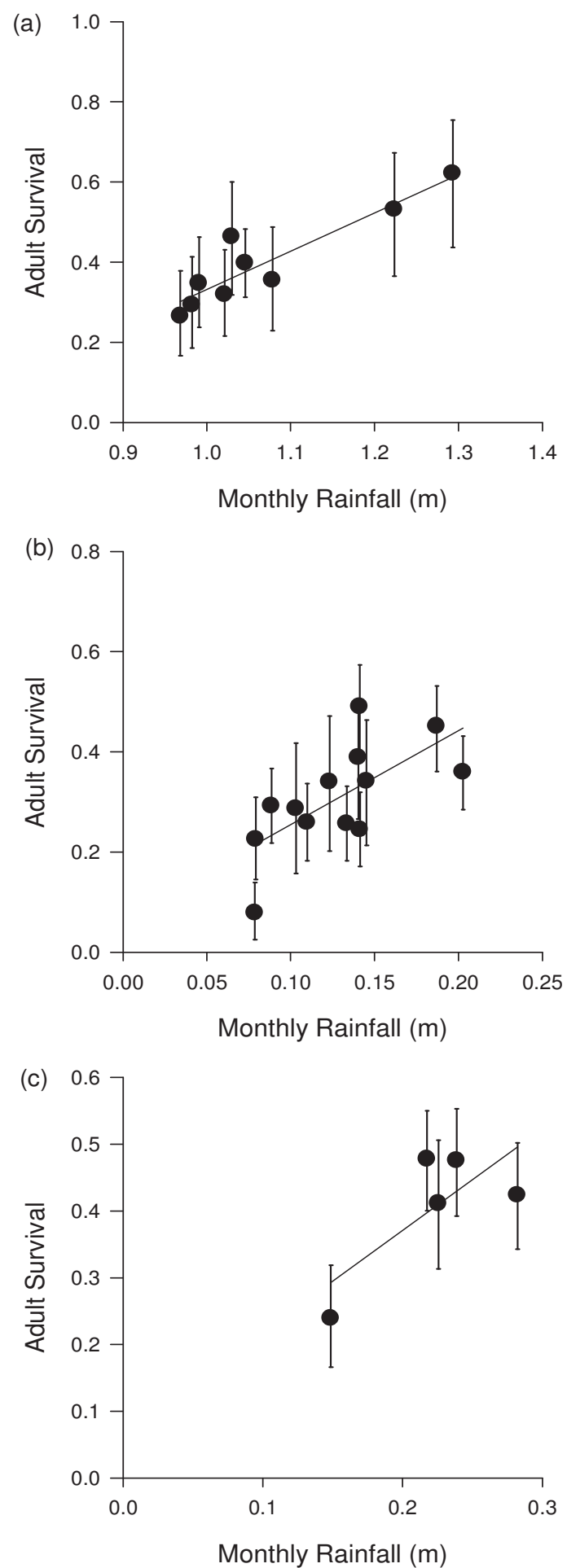

Figure 4. Relationships between adult survival of hirundines and rainfall on the wintering grounds. Each point represents a year, and bars \pm 1 standard error. (a) House Martin and maximum monthly rainfall during the wet season; slope of best-fit line $=0.97 \pm 0.16, R^{2}=0.84$, $P<0.001$. (b) Sand Martin and minimum monthly rainfall during the wet season; slope of best-fit line $=2.01 \pm 0.61, R^{2}=0.50, P<0.01$. (c) Swallow and mean monthly rainfall during the early austral summer; slope of best-fit line $=1.50 \pm 0.80, R^{2}=0.54, P=0.15$. 
estimates of survival derived from the recovery of dead birds in Britain: 0.379 for Swallow (Siriwardena et al 1998), 0.354 for Sand Martin and 0.366 for House Martin (both Dobson 1990); these figures for martins were derived using now-utdated methods, however, so may be underestimates. Ring-recovery estimates of survival are likely to be closer to the 'true' survival rate because, being based upon national populations, they are much less affected by immigration and emigration than are mark-recapture estimates. The close agreement between the recapture and recovery estimates suggests that hirundines are highly site faithful, ie emigration is limited. Supporting this, Paradis et al (1996) found that mean breeding dispersal was only 0.6 $\mathrm{km}$ for House Martin and for Swallow and $1.2 \mathrm{~km}$ for Sand Martin; hence, for these species at least, mark-recapture studies may come close to monitoring 'true' survival.

There was some evidence of a decline in survival for House Martin but, because this does not correspond with a period of major population decline, the significance of this result for the national population is unclear. Survival rates of migratory birds may be influenced by factors on the breeding or non-breeding grounds, during the journey between them, or (most probably) by a combination of these. It has been demonstrated previously that rainfall on both the breeding and non-breeding grounds affects the survival of Palaearctic hirundine species, particularly Sand Martins, and other species, such as warblers, probably through impacts on vegetation and the availability of insect prey (Peach et al 1991; Szép 1995; Cowley \& Siriwardena 2005). Sand Martins spend the northern winter in generally arid areas, whereas House Martins winter in wetter areas farther east (although the core wintering areas for these species are imprecisely known). In arid areas, a certain minimum threshold precipitation is required to promote vegetation growth, and hence insect abundance. Consequently it may be that, during periods of water stress, vegetation growth is slowed sufficiently to affect the insect abundance of the subsequent months. In moister areas with a higher water table, water will not be as limiting, so even in times of relatively low rainfall, food resources may still be common (Poulin et al 1992). Although rainfall is an important variable in determining survival for both species, the way this is manifested seems to differ between climatic regions. That rainfall in Britain is not correlated with survival may suggest that in temperate climes food abundance is less limiting or, perhaps more likely, that the determinants of insect abundance are rather more complex.

These results show, at least for these species, that the RAS scheme provides a useful way of monitoring survival rates, that these are broadly comparable across sites within species and that they correlate with environmental factors. As the scheme develops, with more sites and longer runs of data, it will be interesting to see whether survival rates really are comparable across the country, or whether regional variation can be detected. The estimation of survival rates was made more difficult by the fact that recapture rates varied between years within a site, and thus required several parameters to account for what is, in effect, a nuisance variable. In developing RAS further, one would ideally want to encourage ringing of a greater number of birds and a more constant effort between years in ringing and recapturing birds (which may be practically difficult). Whilst RAS ringers are encouraged to record the number of hours they spend on fieldwork each year, insufficient data were available to include in these analyses, in part because we used data from before the formal start of RAS. Preliminary analyses, restricted to those sites where such data were available suggested that recapture rates were positively correlated with recorded effort, and that using this information could greatly increase the precision with which survival rates could be estimated.

\section{ACKNOWLEDGEMENTS}

We would like to thank all the RAS ringers for their contributions to the scheme, particularly those whose data were used in these analyses. We are grateful to Tim Mitchell of the Tyndall Centre for Climate Change Research for providing the global rainfall data and to the Hadley Centre for the England \& Wales data. The Ringing Scheme (of which RAS is part) is funded jointly by the BTO, the Joint Nature Conservation Committee (on behalf of Natural England, Scottish Natural Heritage, the Countryside Council for Wales and the Environment and Heritage Service in Northern Ireland) and the ringers themselves. We thank Humphrey Crick, Steve Freeman, Stuart Newson, Gavin Siriwardena and two referees for their helpful comments on an earlier version of this paper.

\section{REFERENCES}

Baillie, S.R., Marchant, J.H., Crick, H.Q.P., Noble, D.G., Balmer, D.E., Barimore, C., Coombes, R.H., Downie, I.S., Freeman, S.N., Joys, A.C., Leech, D.I., Raven, M.J., Robinson, R.A. \& Thewlis, R.M. (2007) Breeding Birds in the Wider Countryside: their conservation status 2006. Research Report 470. British Trust for Ornithology, Thetford. (www.bto.org/birdtrends)

Burnham, K.P., Anderson, D.R., White, G.C., Brownie, C. \& Pollock, K.P. (1987) Design and analysis of methods for fish survival experiments based on release-recapture. American Fisheries Society Monographs 5, 1-437.

Cowley, E. \& Siriwardena, G.M. (2005) Long-term variation in survival rates of Sand Martins Riparia riparia: dependence on breeding and wintering ground weather, age and sex, and their population consequences. Bird Study 52, 237-251.

Cramp, S. (ed) (1988) Handbook of the Birds of Europe, the Middle East and North Africa: the birds of the Western Palearctic. Volume V. Tyrant Flycatchers to Thrushes. Oxford University Press, Oxford. 
Crick, H.Q.P., Harrison, J.G. \& Jenkins, M.D. (1977) Sand Martin ringing results from the Sevenoaks Reserve 1961-77. Kent Bird Report 25, $1-10$.

Dobson, A.P. (1990) Survival rates and their relationship to lifehistory traits in some common British birds. Current Ornithology $\mathbf{7}$, 115-146.

Frampton, G.K., van den Brink, P.J. \& Gould, P.J.L. (2000) Effects of spring drought and irrigation on farmland arthropods in southern Britain. Journal of Applied Ecology 37, 865-883.

Lebreton, J.-D., Burnham, K.P., Clobert, J. \& Anderson, D.R. (1992) Modelling survival and testing biological hypothesis using marked animals: a unified approach with case studies. Ecological Monographs 62, 67-118.

Mitchell, T.D. \& Jones, P.D. (2005) An improved method of constructing a database of monthly climate observations and associated highresolution grids. International Journal of Climatology 25, 693-712.

Møller, A.P. \& Szép, T. (2005) Rapid evolutionary change in a secondary sexual character linked to climatic change. Journal of Evolutionary Biology 18, 481-495.

Paradis, E., Baillie, S.R., Sutherland, W.J. \& Gregory, R.D. (1996) Patterns of natal and breeding dispersal in birds. Journal of Animal Ecology 67, 518-536.

Peach, W.J., Baillie, S. \& Underhill, L. (1991) Survival of Sedge Warblers Acrocephalus schoenobaenus in relation to West African rainfall. Ibis 133, 300-305.

Peach, W.J., Buckland, S.T. \& Baillie S.R. (1996) The use of constanteffort mist-netting to measure between-year changes in the abundance and productivity of common passerines. Bird Study 43, 142-156.

Poulin, B., Lefebvre, G. \& McNeil, R. (1992) Tropical avian phenology in relation to abundance and exploitation of food resources. Ecology 73, 2295-2309.
Robinson, R.A., Crick, H.Q.P. \& Peach, W.J. (2003) Population trends of swallows breeding in Britain. Bird Study 50, 1-7.

Sanderson, F.J., Donald, P.F., Pain, D.J., Burfield, I.J. \& van Bommel, F.P.J. (2006) Long-term population declines in AfroPalearctic migrant birds. Biological Conservation 131, 93-105.

Sherry, T.W. \& Holmes, R.T. (1996) Winter habitat quality, population limitation, and conservation of Neotropical-Nearctic migrant birds. Ecology 77, 36-48.

Siriwardena, G.M., Baillie, S.R. \& Wilson J.D. (1998) Variation in the survival rates of some British passerines with respect to their population trends on farmland. Bird Study 45, 276-292.

Szép, T. (1995) Relationship between west African rainfall and the survival of central European Sand Martins Riparia riparia. Ibis 137, 162-168.

Turner, A. (2006) The Barn Swallow. T. \& A.D. Poyser, London.

Wernham, C.V., Toms, M.P., Marchant, J.H., Clark, J.A., Siriwardena, G.M. \& Baillie, S.R. (eds) (2002) The Migration Atlas: movements of the birds of Britain and Ireland. T. \& A.D. Poyser, London.

White, G.C. \& Burnham, K.P. (1999) Program MARK: survival estimation from populations of marked animals. Bird Studies $\mathbf{4 6}$ (suppl.) 120-139.

Wigley, T.M.L. \& Jones, P.D. (1987) England and Wales precipitation: a discussion of recent changes in variability and an update to 1985 . Journal of Climatology 7, 231-246.

Wolda, H. (1978) Seasonal fluctuations in rainfall, food and abundance of tropical insects. Journal of Animal Ecology 47, 369-381. 